Sammlung Metzler Band 277 
Knut Hickethier

\section{Film- und Fernsehanalyse}

3., überarbeitete Auflage

Verlag J.B. Metzler Stuttgart - Weimar 
Der Autor

Knut Hickethier, geb. 1945; Studium der Literaturwissenschaft und Medienwissenschaft in Berlin; 1982 Habilitation; seit 1990 Lehrstuhlvertretung und Gastprofessur für Medienwissenschaft an der Universität Marburg; seit 1994 Professor für Medienwissenschaft an der Universität Hamburg; bei J.B. Metzler sind erschienen: Geschichte des deutschen Fernsehens, 1998. Das Fernsehspiel der Bundesrepublik, 1980.

Die Deutsche Bibliothek - CIP-Einheitsaufnahme

Hickethier, Knut:

Film- und Fernsehanalyse / Knut Hickethier.

- 3., überarb. Aufl..

- Stuttgart ; Weimar : Metzler, 2001

(Sammlung Metzler ; Bd. 277 : Realien zur Literatur)

ISBN 978-3-476-13277-2

SM 277

ISBN 978-3-476-13277-2

ISBN 978-3-476-02752-8 (eBook)

DOI $10.1007 / 978-3-476-02752-8$

ISSN 05583667

Dieses Werk einschließlich aller seiner Teile ist urheberrechtlich geschützt. Jede Verwertung außerhalb der engen Grenzen des Urheberrechtsgesetzes ist ohne Zustimmung des Verlages unzulässig und strafbar. Das gilt insbesondere für Vervielfältigungen, Übersetzungen, Mikroverfilmungen und die Einspeicherung und Verarbeitung in elektronischen Systemen.

(C) 2001 Springer-Verlag GmbH Deutschland

Ursprünglich erschienen bei J.B. Metzlersche Verlagsbuchhandlung und Carl Ernst Poeschel Verlag GmbH in Stuttgart 2001

www.metzlerverlag.de info@metzlerverlag.de 


\section{Inhalt}

I. Einleitung $\ldots \ldots \ldots \ldots \ldots \ldots \ldots \ldots \ldots \ldots \ldots \ldots$

II. Gegenstandseingrenzungen

Film - Fernsehen - Audiovision ............ 5

1. Medium und Kunst ................... 6

2. Film und Fernsehen als Kommunikation ........... 9

3. Öffentlichkeit - Film, Fernsehen, Video . . . . . . 13

4. Medien als Manipulationsinstrument? . . . . . . . 17

5. Dispositive des Kinos und des Fernsehens ......... 19

6. Apparat und Programm ................ 21

7. Film und Fernsehen als Text und Erzählung ....... 23

III. Methodische Aspekte ................ 26

1. Erkenntnisorientierte Analyse............... 26

2. Inhaltsanalyse oder Hermeneutik . . . . . . . . . 30

3. Zum Filmprotokoll $\ldots \ldots \ldots \ldots \ldots \ldots \ldots \ldots . \ldots . \ldots$

4. Computergestützte Filmanalyse $\ldots \ldots \ldots \ldots \ldots \ldots .40$

IV. Zur Analyse des Visuellen................. 42

1. Das Bild ........................ 42

Das fotografische Bild ................... 44

Das kinematografische Bild ................ 45

Rahmen ......................... 46

Format................... 47

Teil und Ganzes innerhalb des Bildformats . . . . . . . . 49

Komposition..................... 50

Die Ordnung der Dinge im Bild und ihre Bewegung ..... 52

Vom Bild zur Bilderfolge ................ 53

2. Kategorien zur Beschreibung des filmischen Bildes .... 55

Größe der Einstellung als Nähe-Distanz-Relation . . . . . . 57

Kameraperspektive ....................61 61

Bewegungen von Kamera und Objekt ............ 62

Bewegungsrichtungen .................... 64

Dynamik des Bewegungsflusses............... 67

Die Veränderung der Begriffe durch die Technik . . . . . 68

3. Bildraum, Architektur und Licht . . . . . . . . 70 
Inhalt

Der $>$ mechanische Bildraum............... 71

Natur und gebauter Umraum . . . . . . . . . . . . 74

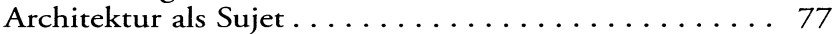

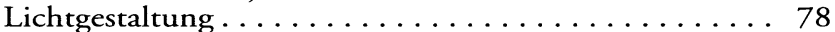

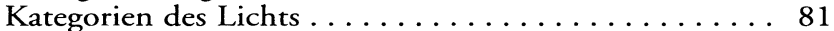

Narrativer Raum. . . . . . . . . . . . . . . . 84

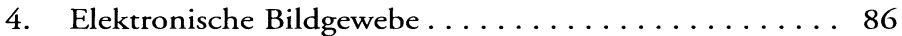

Das Fernsehbild . . . . . . . . . . . . . . . . 87

Stanzbilder, elektronische Texturen, Bildgewebe .... 89

V. Zur Analyse des Auditiven .............. 94

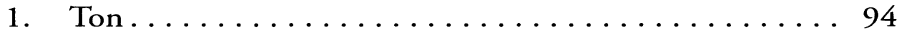

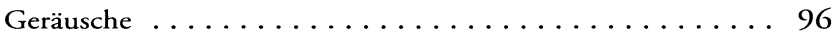

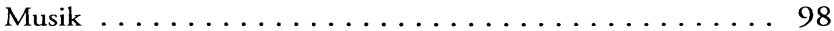

2. Sprache im Film .................. 102

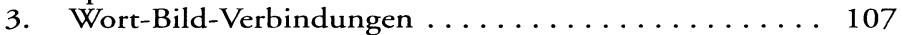

VI. Zur Analyse des Narrativen . . . . . . . . . . . 110

1. Erzählen und Darstellen . . . . . . . . . . . . . 110

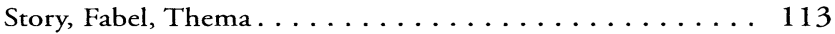

Bedeutungsschichten ................ 115

Denotation und Konnotation . . . . . . . . . . . 116

Gestaltete Abfolge . . . . . . . . . . . . . . . . . 119

2. Dramaturgie .................... 121

Geschlossene und offene Form . . . . . . . . . . . 122

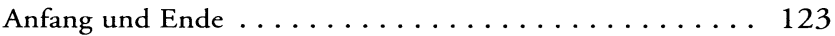

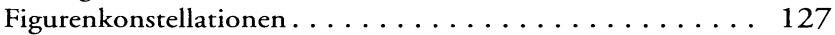

3. Erzählstrategien . . . . . . . . . . . . . . 129

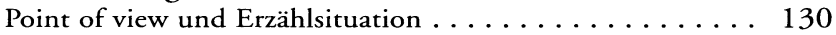

Erzählzeit und erzählte Zeit . . . . . . . . . . . 133

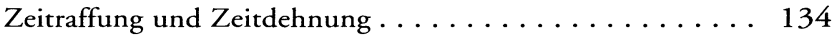

Vorgreifen und Rückwenden ... . . . . . . . . . . 135

Gegenwart und Gleichzeitigkeit . . . . . . . . . . . 139

4. Montage und Mischung . . . . . . . . . . . . 144

Montage der Einstellungen . . . . . . . . . . . . . 145

Montage der Sequenzen . . . . . . . . . . . . . . . 146

Dramaturgie, Erzählen und Montage als Einheit. . . . . . 148

Der unsichtbare Schnitt . . . . . . . . . . . . . . . . 149

Der unsichtbare Schnitt als filmischer Realismus? . . . . . . 155

Montage als Kollision ................ 156

Montage des Autorenfilms . . . . . . . . . . . . 157

Montagestile - Filmstile . . . . . . . . . . . . . . . 159 
Bildmischung - Transparenz des Televisuellen . . . . . 160

Die Materialität elektronischer Bilder . . . . . . . . . . 162

Innere Montage . . . . . . . . . . . . . . . 164

Montage im postklassischen Hollywood-Film . . . . . . . 167

VII. Schauspielen und Darstellen

in Film und Fernsehen . . . . . . . . . . . . . . . . . 169

1. Die Präsenz des Darstellers . . . . . . . . . . . . . . 169

2. Produktion und Rezeption ............. 170

Unterspielen . . . . . . . . . . . . . . . 172

3. Darstellungsstile im Film . . . . . . . . . . . 173

Darsteller und Rolle . . . . . . . . . . . . . . . . . 175

Sichtbarmachen des Unsichtbaren . . . . . . . . . . 179

4. Darstellen im Fernsehen . . . . . . . . . . . 182

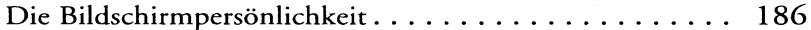

Der Politdarsteller . . . . . . . . . . . . . . 188

VIII. Dokumentarisch - fiktional

Gattungen und Programmformen . . . . . . . . . 190

1. Fiktion - Dokumentation .............. 191

2. Kinofilm - Fernsehspiel - Fernsehfilm . . . . . . 193

Film-Fernseh-Koproduktion . . . . . . . . . . . 196

3. Die Serie . . . . . . . . . . . . . . . . . . . 197

4. Dokumentarfilm - Feature - Dokumentation .... 200

5. Dokumentarisch-fiktionale Mischformen ... . . . . . 204

6. Spielshow - Game Show . . . . . . . . . . . . . 207

IX. Werk, Genre und Programm ........... 210

1. Oeuvre..................... 210

2. Genre.................... 213

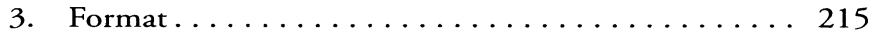

4. Programm .................. 216

Das Programm als große Erzählung . . . . . . . 217

Programmverbindungen ................ 219

5. Entgrenzung und Verfestigung .......... 221

X. Literaturverzeichnis ... . . . . . . . . . . . . 224

Sachregister .................... 238 